OPEN ACCESS

Edited by:

Chad Slawson,

University of Kansas Medical Center

Research Institute, United States

Reviewed by:

Edgar Zenteno,

National Autonomous University of

Mexico, Mexico

Tiago Cardoso Alves,

University Hospital Carl Gustav Carus,

Germany

*Correspondence: Elizabeth C. Jury

e.jury@ucl.ac.uk

Inés Pineda-Torra

i.torra@ucl.ac.uk

Specialty section:

This article was submitted to Molecular and Structural

Endocrinology,

a section of the journal

Frontiers in Endocrinology

Received: 09 December 2020

Accepted: 22 March 2021

Published: 13 April 2021

Citation:

Pineda-Torra I, Siddique S, Waddington $K E$, Farrell $R$ and

Jury EC (2021) Disrupted Lipid Metabolism in Multiple Sclerosis: A

Role for Liver $X$ Receptors?

Front. Endocrinol. 12:639757. doi: 10.3389/fendo.2021.639757

\section{Disrupted Lipid Metabolism in Multiple Sclerosis: A Role for Liver X Receptors?}

\author{
Inés Pineda-Torra ${ }^{1 *}$, Sherrice Siddique ${ }^{2}$, Kirsty E. Waddington ${ }^{1,2}$, Rachel Farrell ${ }^{3}$ \\ and Elizabeth C. Jury ${ }^{2 *}$ \\ ${ }^{1}$ Centre for Cardiometabolic and Vascular Medicine, Department of Medicine, University College London, London, \\ United Kingdom, ${ }^{2}$ Centre for Rheumatology, Department of Medicine, University College London, London, United Kingdom, \\ ${ }^{3}$ Department of Neuroinflammation, Institute of Neurology and National Hospital of Neurology and Neurosurgery, University \\ College London, London, United Kingdom
}

Multiple sclerosis (MS) is a chronic neurological disease driven by autoimmune, inflammatory and neurodegenerative processes leading to neuronal demyelination and subsequent degeneration. Systemic lipid metabolism is disturbed in people with MS, and lipid metabolic pathways are crucial to the protective process of remyelination. The lipidactivated transcription factors liver $X$ receptors (LXRs) are important integrators of lipid metabolism and immunity. Consequently, there is a strong interest in targeting these receptors in a number of metabolic and inflammatory diseases, including MS. We have reviewed the evidence for involvement of $L X R$-driven lipid metabolism in the dysfunction of peripheral and brain-resident immune cells in MS, focusing on human studies, both the relapsing remitting and progressive phases of the disease are discussed. Finally, we discuss the therapeutic potential of modulating the activity of these receptors with existing pharmacological agents and highlight important areas of future research.

Keywords: liver $\mathbf{X}$ receptor, multiple sclerosis, lipid metabolism, nuclear receptor, cholesterol

\section{INTRODUCTION}

Multiple sclerosis (MS) is a chronic degenerative disease of the central nervous system (CNS) and a major cause of neurological disability amongst young adults (1). The disease course is heterogeneous, characterized by acute onset neurological symptoms (relapses) and steady accrual of disability (progression). The underlying pathophysiology is complex and differences exist in the mechanisms causing relapse-predominant MS (RMS) and progressive neurodegeneration (either primary progressive where progression occurs from disease onset or secondary progressive where progression follows a period of relapsing disease) (2). In RMS, relapses are associated with autoinflammatory processes driven by defects in immune regulation and activation and, migration of multiple effector immune cells across the blood brain barrier (BBB) into the CNS. Interactions between autoreactive immune cells and CNS resident cells, such as microglia and astrocytes, result in the release of inflammatory mediators that exacerbate localized inflammation. These inflammatory episodes resolve and lesions remyelinate, however subsequent neuronal degeneration can lead to persistent disability $(3,4)$. 
The mechanisms driving accrual of disability in progressive MS are not well characterized but include neuro-axonal, oligodendrocyte and astrocyte damage leading to neurodegeneration. This is mediated by compartmentalized chronic inflammation within the CNS, involving the formation of CNS lymphoid-like structures and activation of CNS-resident innate cells (including microglia); notably, unlike RMS, the BBB is less permeable to immune cells migrating from the periphery (5-7).

Evidence supports a role for lipid metabolism (including changes in cholesterol, oxysterols, sphingolipids and fatty acids) not only in MS pathogenesis, but also as biomarkers of disease activity and progression and as treatment targets (8-14). One hypothesis is that abnormal lipid-mediated signaling in immune cells could contribute to MS pathogenesis (15). Lipid metabolism plays a crucial role in immune cell activation, differentiation and effector function (16). For example, activated T-cells have higher plasma membrane cholesterol (17) and fatty acid levels (18) and, fatty acid synthesis controls lineage differentiation into pro-inflammatory T-helper (Th)17 cells (19). Furthermore, modulation of plasma membrane lipid rafts, signaling microdomains in the plasma membrane enriched with lipids such as cholesterol and glycosphingolipids, influence immune cell differentiation and function $(20,21)$ with potentially pathogenic consequences (22). Conversely, manipulation of plasma membrane lipids can restore immune cell function in autoimmunity and cancer (23-25).

Interestingly, statins, inhibitors of the cholesterol biosynthesis enzyme 3-Hydroxy-3-Methylglutaryl-CoA Reductase-a widely used class of lipid lowering therapy, have been extensively studied in MS (26). Notably, a phase-II clinical trial showed that high dose simvastatin (CNS-penetrant statin) attenuated brain atrophy and disease progression without adverse effects in secondary progressive MS patients (27). A phase-III clinical trial is underway (MS-STAT2; NCT03387670, http://www.isrctn.com/ISRCTN82598726). Statins have pleiotropic effects on the immune system through the simultaneous promotion of Th2 differentiation, inhibition of Th1 mediated damage and reduction of neurotoxic proinflammatory molecules (28). Simvastatin also inhibits secretion of cytokines necessary for Th1 and Th17 differentiation in RMS patients (29) by inhibiting the interferon regulatory factor-4 transcription factor (30). Statins may also work through inhibition of mevalonate pathwayderived isoprenoids that mediate membrane association of certain signaling proteins, rather than direct inhibition of cholesterol itself $(31,32)$.

How disrupted lipid metabolism influences disease processes in MS remains uncertain. The lipid-activated nuclear receptors, liver $\mathrm{X}$ receptors (LXRs) and peroxisome proliferator-activated receptors $(33,34)$, are responsible for integration of lipid metabolism signaling in multiple immune and neuronal cell types, and could both play an important role $(33,35)$. This mini review presents evidence to support a role for LXRs in dysregulated lipid metabolism and immunopathogenesis in MS.

\section{LIVER X RECEPTORS}

LXRs are nuclear transcription factors with key functions in lipid metabolism and cholesterol homeostasis (36-39). Two isoforms exist, LXR $\alpha$ and LXR $\beta$, encoded by $N R 1 H 3$ and $N R 1 H 2$ genes respectively (40). They share $78 \%$ of their amino acid sequence identity but are differentially expressed; LXR $\alpha$ in metabolically active tissues (including liver, adipose tissue, macrophages, lung, intestine) while LXR $\beta$ is expressed ubiquitously. LXRs are activated by oxidized derivatives of cholesterol (oxysterols) (41-43) and intermediates of cholesterol biosynthesis $(44,45)$. Synthetic ligands for LXRs have been developed and used to understand LXR function, the most common being GW3965 and T0901317 (later reported to also act on other nuclear receptors) (46-49).

Cholesterol forms an essential component of cellular membranes and its oxysterol derivatives regulate many cellular processes. Cholesterol overload is toxic to cells, therefore pathways responsible for its generation are coupled to those responsible for cellular efflux (removal) and are tightly controlled, to ensure homeostasis (17). LXRs regulate intracellular lipid (including cholesterol) metabolism through a number of pathways including reverse cholesterol transport via the ATP binding cassette transporters (ABC)A1 (50) and ABCG1 (51) which promote cholesterol removal to the liver for catabolism and excretion by high density lipoprotein (HDL) particles. LXRs regulate the transcription of numerous genes involved in this process including, apolipoprotein-A1 (Apo-A1), apolipoprotein-E (Apo-E) $(52,53)$ and cholesteryl ester transfer protein (54). Other processes regulated by LXRs include; inducible degrader of the LDL receptor (55); Niemann Pick type-C proteins-1 and 2 involved in the lysosomal/late endosomal trafficking and recycling of intracellular lipids (56); fatty acid metabolism both de novo synthesis or through the Sterol Regulatory Element Binding Protein (SREBP)1, fatty acid synthase (FASN (57)) and fatty acid desaturation (FADS1, FADS2), elongation (elongation of very long-chain fatty acids protein) and phospholipid remodeling (Phospholipid transfer protein and lysophosphatidylcholine acyltransferase-3) (58-60).

The brain contains $20 \%$ of body cholesterol and $~ 70-80 \%$ of cholesterol in the brain comprises an essential component of myelin in neuronal cells (61). The BBB prevents cholesterol transfer from the circulation into the brain, therefore brain cholesterol is synthesized de novo (62) via the 3-hydroxy-3-methylglutarylcoenzyme-A reductase pathway. Cholesterol produced by glial cells is effluxed via ABCA1 to HDL-like molecules such as Apo$\mathrm{E}$, where it is taken up by LDL-receptors and other lipoprotein receptors in neurons (which have a high demand for cholesterol due to the large area of membrane in axons and dendrites). Intracellular cholesterol is transported via Niemann Pick type-C proteins. Conversely, excess cholesterol is eliminated via hydroxylation to 24(S)-hydroxycholesterol (catalyzed by cholesterol 24-hydroxylase), a polar oxysterol and the most abundant oxysterol in the brain, which crosses the $\mathrm{BBB}$, enters the circulation, and is eliminated by the liver $(61,63)$ (Figure 1A).

Oligodendrocytes maintain myelination and remyelination processes within the CNS and LXR-regulated lipid metabolism 
A Fatty Acid Synthesis

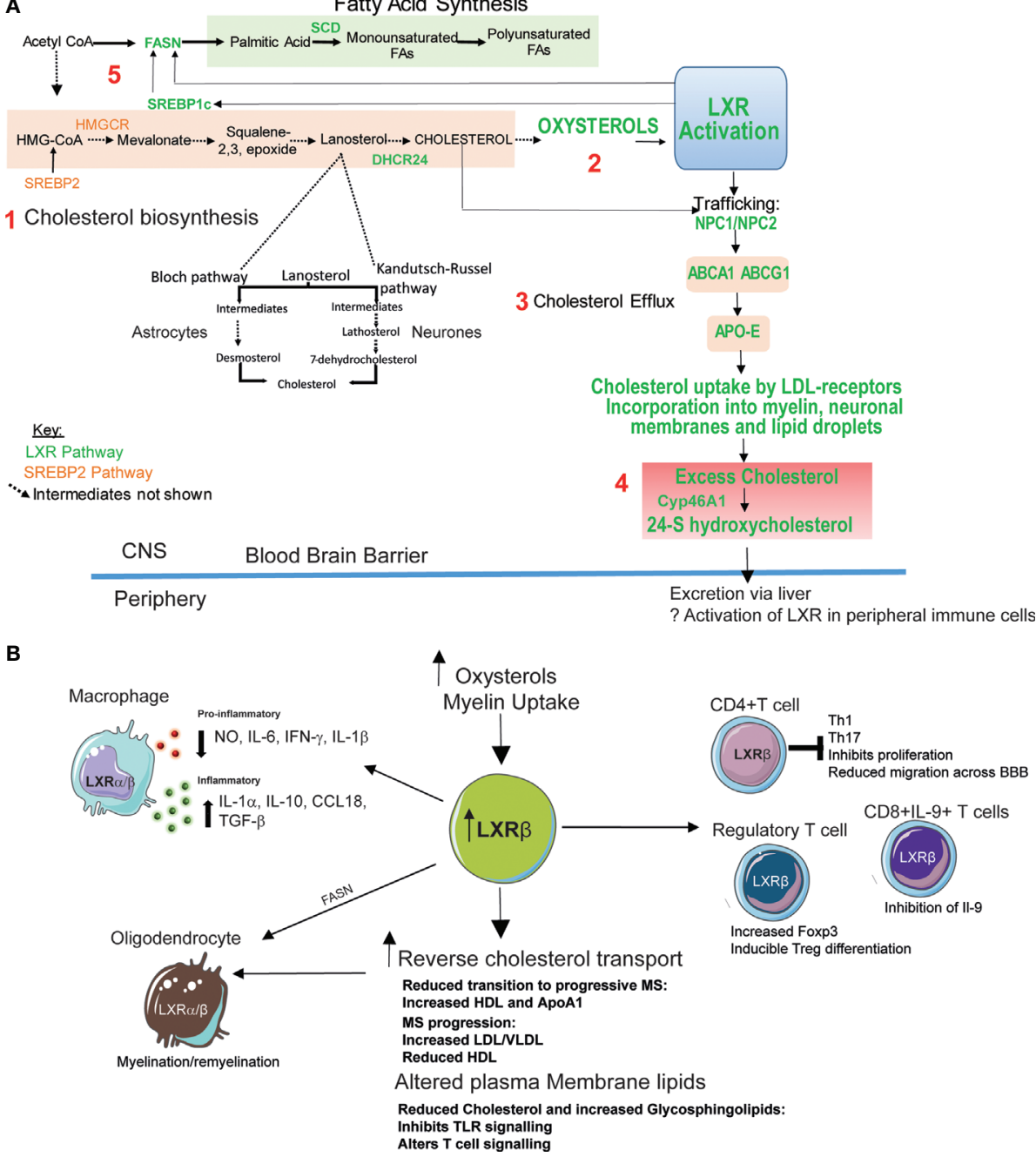

FIGURE 1 | Potential therapeutic roles of LXR activation in MS. (A) Intracellular cholesterol levels in the brain are tightly regulated by two transcription factors (61): 1. Liver-X-receptor (LXR) and sterol response element binding-protein 2 (SREBP-2). SREBP2 upregulates genes involved in cholesterol biosynthesis. Cholesterol in the brain is produced de novo mainly by glial cells such as astrocytes using the Bloch pathway. Neurons which have a high cholesterol requirement produce less cholesterol via the Kandutsch-Russell pathway. 2. LXR is activated by by-products of cholesterol synthesis (oxysterols). 3. LXR activation promotes cholesterol export via intracellular cholesterol transporter Niemann Pick Type C1 and 2 (NPC1/NPC2), and ATP binding cassette (ABC) A1 and ABCG1 which efflux cholesterol from the plasma membrane to high density lipoprotein (HDL)-like lipoproteins including apolipoprotein-E (Apo-E). 4. Cholesterol is taken up by cells via lipoprotein receptors. Excess cellular cholesterol (potentially generated by neurodegeneration processes) is stored in lipid droplets or converted into oxysterols. 24-S hydroxycholesterol is the most abundant oxysterol in the brain and its production is catalyzed by the enzyme Cyp46A1 (cholesterol 24S-hydroxylase). 24-S hydroxycholesterol is able to cross the blood brain barrier to the periphery where it is degraded in the liver. 5 . LXR also promotes fatty acid synthesis through its target genes SREBP1c, fatty acid synthase (FASN) and stearoyl-CoA desaturase (SCD). Plasma membrane levels of cholesterol and fatty acids can influence lipid rafts-membrane microdomains important for immune synapse formation and immune cell activation and function. Fatty acid (glycosphingolipid) abundance and composition can also influence plasma membrane fluidity (64). (B) LXR $\beta$ expression is elevated in peripheral blood mononuclear cells from MS patients potentially due to increased levels of oxysterols including 24S-hydroxycholesterol. Increased LXR activation can also be triggered by myelin uptake by glial cells in the central nervous system (CNS). LXR activation induces reverse cholesterol transport (A, 4). Patients with MS have altered lipoprotein profiles which may reflect defects in the efficacy of this process. MS progression is associated with reduced levels of high density lipoproteins (HDL)- responsible for effective cholesterol efflux. LXR activation also induces fatty acid and glycosphingolipid biosynthesis (A, 5). Changes in cellular cholesterol and glycosphingolipids can alter immune cell function by altering cell signaling and downstream functions including proliferation and cytokine production. In T-cells LXR activation reduces T-cell infiltration into the CNS (65) and inhibits naïve CD4+ T-cell differentiation towards an inflammatory Th17 phenotype (66) and suppressed IL-9 producing CD8+ T cells during anti-tumor responses (67). LXR activation is crucial for Treg function (68). LXR activation stimulates oligodendrocyte myelin production and remyelination processes (69). Mechanisms include stimulation of reverse cholesterol transport and fatty acid synthesis. LXR activation leads to the repression of inflammatory responses through the downregulation of pro-inflammatory genes including inducible nitric oxide synthase (NO), interleukin (IL)-1 $\beta$, IL-6 and tumor necrosis factor- $\alpha$. Myelin uptake by macrophages activates LXR and suppresses the production these pro-inflammatory mediators These myelin-laden macrophages, express high levels of antiinflammatory IL-1-receptor- $\alpha$, IL-10, CC-chemokine ligand- 18 and transforming growth factor- $\beta$ (70). 
pathways are crucial to their function $(71,72)$. CNS myelination is reduced in LXR knockout mice, conversely LXR activation stimulates oligodendrocyte maturation, myelin production and remyelination processes (69). Mechanisms include stimulation of reverse cholesterol transport via LXR target genes including ABCA1 and Apo-E, which restore remyelination in aged mice (12) and fatty acid synthesis; depletion of the LXR-target gene FASN blocked oligodendrocyte myelination and remyelination in the murine CNS (73).

\section{Cholesterol, Oxysterols and LXR in MS}

The relationship between disrupted serum cholesterol levels and adverse clinical outcomes in MS has been observed in several studies (74). Notably elevated apolipoprotein-B (Apo-B) (the major component of low/very low density lipoprotein cholesterol, LDL/VLDL) in clinically isolated syndrome (before confirmed MS diagnosis) correlated positively with increased Expanded Disability Status Scale (EDSS) indicating that cholesterol levels could serve as biomarkers for disease progression $(74,75)$, even accounting for age as a confounder. Similarly, in RMS, elevated serum LDL correlated positively with disease activity assessed by new MRI lesions $(10,11)$; increased LDL, total cholesterol and Apo-B levels were independently associated with higher EDSS score $(9,76)$; as were elevated VLDL subset levels (77). Conversely, high serum HDL was associated with reduced BBB injury and reduced inflammatory infiltrate in the cerebrospinal fluid (78). In RMS, increasing HDL and Apo-AI levels over time predicted a reduced likelihood of transition to secondary progressive disease and reduced brain atrophy (79). Also a greater reduction in $\mathrm{HDL}$ following interferon- $\beta$ treatment in RMS patients predicted lower rates of future brain atrophy (10).

Differential patterns of oxysterol expression are also described in MS depending on the stage of disease $(80,81)$. Higher circulating oxysterols, notably, 24S-hydroxycholesterol, are thought to reflect elevated brain cholesterol metabolism and ongoing neurodegeneration $(74,81,82)$. RMS patients progressing to secondary progressive disease over 5 years had higher CNS-derived serum 24S-hydroxycholesterol and Apo-B and reduced 7-ketocholesterol (83). While one study shows increased serum 7 -ketocholesterol in patients with primary progressive disease (80). In older patients with RMS and those with primary progressive MS, serum 24S-hydroxycholesterol levels are low $(84,85)$ most likely due to increased brain atrophy and neuronal loss.

How changes in systemic cholesterol and oxysterols relate to LXR function in MS remain uncertain. Changes in oxysterol availability in MS (83) could lead to modulation of LXR signaling and influence subsequent immune cell function. For example, Th17 cells upregulate an enzyme that sulfates oxysterols (SULT2B1), thereby inactivating them as LXR ligands and driving preferential activation of ROR $\gamma t$ (essential for Th17 function) instead of LXR (86). Also cholesterol/oxysterols are tightly suppressed in a subset of IL- 9 producing $\mathrm{CD}^{+} \mathrm{T}$ cells to prevent transrepression of the Il9 locus by LXR (67) and differentiated type-1 regulatory T-cells (Tregs) upregulate 25hydroxycholesterol to limit IL-10 production (87).
LXR $\beta$ expression is elevated in peripheral blood mononuclear cells from MS patients compared to healthy controls supporting a role for LXR in immune cell dysregulation (88) and LXR signaling was upregulated in T-cells during the adoptive transfer EAE (experimental autoimmune encephalomyelitis) model of MS (89). Interestingly, absence of LXR $\alpha$ in brain endothelial cells in EAE resulted in more severe disease, increased $\mathrm{BBB}$ permeability and CNS inflammatory infiltrate (90).

MS patients are also characterized by other defects in lipid metabolism. A lipidomic analysis of $\mathrm{CD} 4^{+}$lymphocytes from MS patients identified altered phospholipids and elevated cardiolipins, potentially reflecting mitochondrial dysfunction (91). Glycosphingolipids (including ceramides and downstream metabolites hexosylceramide and lactosylceramide) are dysregulated in MS serum, plasma and immune cells (92-94). For example, decreased ceramides in white blood cells from MS patients were associated with impaired granulocyte-colony stimulating factor signaling and impaired neutrophil migration (93) and altered glycosphingolipid synthesis induced pathogenic inflammatory processes in astrocytes in a murine model of secondary progressive MS (95). Our recent work shows that LXR activation accelerates the conversion of ceramide to hexosylceramide (a key event in glycosphingolipid biosynthesis) in human $\mathrm{CD}^{+} \mathrm{T}$-cells. LXR stimulation regulated $\mathrm{CD} 4^{+} \mathrm{T}$-cell function in part by upregulating plasma membrane glycosphingolipids and reducing cholesterol thereby altering T-cell receptor-mediated signalling (96).

Collectively, these studies suggest that disrupted LXR function could be implicated in MS pathogenesis.

\section{Anti-Inflammatory Effects of LXRs in Immune Cells}

LXR activation leads to the repression of inflammatory responses through the downregulation of pro-inflammatory genes including inducible nitric oxide synthase, interleukin (IL)-1 $\beta$, IL-6 and tumor necrosis factor- $\alpha(97-100)$. This was thought to result from a transrepression mechanism involving SUMOylation of ligand-bound LXR. In macrophages, SUMOylation of LXR stabilizes corepressors on the nuclear factor kappa $B(N F-\kappa B)$ transcription factor, therefore dampening the transcription of target genes (101). However, a more recent study demonstrated LXRs ability to repress inflammatory genes in the absence of SUMOylation via the upregulation of the transmembrane cholesterol transporter ABCA1 which increases cholesterol efflux, alters plasma membrane lipid raft composition, and thereby inhibits Tolllike receptor signaling to downstream effectors $N F-\kappa B$ and mitogen-activated protein kinase (64).

The role of microglia (CNS-resident macrophages) in MS is complex; they can be both pathogenic (antigen presentation to T-cells and release of pro-inflammatory cytokines) and antiinflammatory (clearing myelin debris and enabling remyelination) (102). LXR response genes ABCA1 and Apo-E are upregulated in microglia from active demyelinating MS lesions (103). The same study shows that myelin uptake induces production of 27-hydroxycholesterol oxysterol which 
activates LXR $\alpha$ and induces ABCA1 and Apo-E upregulation in human monocyte-derived macrophages. Myelin uptake by macrophages also activates LXR $\beta$ and suppresses the production the pro-inflammatory mediators nitric oxide and IL- 6 and interferon- $\gamma /$ IL- $1 \beta$ signalling (104). These myelin-laden macrophages, termed foamy macrophages, similar to lipid-laden macrophages present in atherosclerotic plaques, and derived from either resident microglia or infiltrating monocytes, have a distinct phenotype characterized by enhanced expression of genes involved in migration, phagocytosis and inflammation as well as genes involved in LXR signaling and cholesterol efflux. Moreover, murine foamy macrophages within MS lesions, defined by elevated HLA-DR and neutral lipid content, express high levels of anti-inflammatory IL-1-receptor- $\alpha$, IL-10, CCchemokine ligand-18 and transforming growth factor- $\beta$ (70). Thus the anti-inflammatory effects of foamy macrophages arise from their response to phagocytosis of myelin, at least in part via LXR activation which suppresses pro-inflammatory mediator release and also inhibits T-lymphocyte proliferation (105).

LXR activation ameliorates EAE severity, potentially by reducing infiltration of T-cells into the CNS (65). Activation of LXR $\alpha$ and LXR $\beta$ can also inhibit naïve $C D 4^{+} \mathrm{T}$-cell differentiation towards an inflammatory Th17 phenotype. This occurs by activating SREBP1a and SREBP1c, which bind to the IL-17 promoter and the aryl hydrocarbon receptor (Ahr) (a positive regulator of Th17 differentiation), thus antagonizing Ahr-mediated IL-17 transcription (66). IL-17 suppression following LXR activation has been reproduced in splenocytes from the EAE model (106) and in in the context of other autoinflammatory diseases (107) such as Behcet's disease. In murine models, LXR is crucial for Treg function by increasing
Foxp3 expression and promoting inducible-Treg differentiation $(68,108)$.Together, these studies demonstrate that activation of LXR influences macrophage and T-cell differentiation and polarization $(66,104,106,107)$. These actions may be protective in the context of MS (Figure 1B).

\section{Therapeutic Activation of LXRs}

Due to their actions on lipid and cholesterol metabolism and the immune system, LXRs have attracted interest as therapeutic targets in neurodegenerative diseases (109, 110). Despite numerous studies showing the benefits of LXR agonism with the first generation of these compounds in experimental models, their translation to clinical practice has proven difficult. Systemic LXR activation promotes hepatic lipid accumulation (steatosis) and hypertriglyceridemia, both risk factors for cardiovascular disease, through the induction of de novo lipogenesis by LXR $\alpha$ in the liver (39). This prompted the development of a new generation of selective agonists, including selective LXR $\beta$ agonists, tissue-selective agonists or agonists targeting the trans-repression/anti-inflammatory actions of LXRs (109) although, to our knowledge, none of these have been tested in preclinical models of MS (Table 1).

Macrophage-selective LXR agonists such as N,N-dimethyl$3 \beta$-hydroxycholenamide (DMHCA) and the desmosterol mimetic methylpiperidinyl-3 $\beta$-hydroxycholenamide (MePipHCA) are examples of transrepression-dissociated agonists that avoid SREBP1c-driven hypertriglyceridemia (114, 115), as does the ATI-111 compound (116). By activating reverse cholesterol transport-related LXR target genes while blocking the processing of SREBP-1c, they act similarly to the endogenous ligands (e.g., desmosterol and oxysterols), which inhibit SREBP

TABLE 1 | Summary of synthetic LXR agonist effects.

\begin{tabular}{|c|c|c|c|c|c|}
\hline Compound & Activity & Status & Disease/Model & Actions & Reference \\
\hline \multirow[t]{2}{*}{ T0901317 } & $\llcorner X R \alpha / \beta$ dual agonist & Preclinical & EAE (MS model) & $\begin{array}{l}\text { Reduced CNS inflammation } \\
\text { Enhanced demyelination } \\
\text { Reduced Clinical severity }\end{array}$ & $(65,66)$ \\
\hline & & Preclinical & WT mice & $\begin{array}{l}\text { Enhanced Myelin gene/protein expression } \\
\text { Increased Oligodendrocyte maturation } \\
\text { Enhanced Remyelination }\end{array}$ & (69) \\
\hline \multirow[t]{2}{*}{ LXR-623 } & $\begin{array}{l}\llcorner X R \alpha / p a r t i a l / \beta \text { full } \\
\text { agonist }\end{array}$ & $\begin{array}{l}\text { Clinical Trial-Phase 1- } \\
\text { Discontinued }\end{array}$ & Atherosclerosis & Adverse neurological effects & $(111)$ \\
\hline & & Preclinical & Glioblastoma & $\begin{array}{l}\text { Enhanced cell death } \\
\text { Increased cholesterol depletion } \\
\text { Enhanced tumor regression } \\
\text { Increased Survival }\end{array}$ & $(112)$ \\
\hline \multirow[t]{2}{*}{ BMS-852927 } & $\begin{array}{l}\text { LXR } \beta / \text { selective } \\
\text { partial agonist }\end{array}$ & $\begin{array}{l}\text { Clinical Trial-Phase 1- } \\
\text { Discontinued }\end{array}$ & Healthy subjects & Increased Cholesterol transport & $(113)$ \\
\hline & & & & $\begin{array}{l}\text { Enhanced Lipogenesis, triglycerides, LDL-C, apoB, apoE, } \\
\text { CETP } \\
\text { Decreased circulating neutrophils }\end{array}$ & \\
\hline \multirow[t]{2}{*}{$\begin{array}{l}\text { DMHCA/ } \\
\text { MePiPMHCA }\end{array}$} & $\begin{array}{l}\text { Transrepression- } \\
\text { selective }\end{array}$ & Preclinical & $\begin{array}{l}\text { Colitis, brain } \\
\text { injury }\end{array}$ & Reduced inflammation & $(114,115)$ \\
\hline & & & & $\begin{array}{l}\text { No induction of hepatic steatosis } \\
\text { SREBP1c inhibition }\end{array}$ & \\
\hline \multirow[t]{2}{*}{ ATI-111 } & $\begin{array}{l}\text { Transrepression- } \\
\text { selective }\end{array}$ & Preclinical & $\begin{array}{l}\text { Atherosclerosis } \\
\text { (Ldlr-null mice) }\end{array}$ & Reduced atherosclerosis & $(116)$ \\
\hline & & & & $\begin{array}{l}\text { Lowers plasma triglycerides and cholesterol } \\
\text { SREBP1c inhibition }\end{array}$ & \\
\hline
\end{tabular}


activation through actions in the endoplasmic reticulum (117). More recent reports on T0901317 and GW3965 showing LXRindependent non-genomic effects in pancreatic $\beta$ cells by interfering with mitochondrial metabolism and cytosolic calcium concentrations (118) highlights the importance of testing the impact of novel LXR agonists in appropriate cellular or experimental systems lacking the receptors or alongside validated LXR antagonists. Whether this is replicated in other cellular systems will require further investigation (119).

Studies with the first generation of LXR agonists suggested their use as novel therapeutic agents for the treatment of MS. LXR activation in EAE dramatically ameliorates demyelination and inflammation in an LXR-dependent manner $(65,66)$. LXR activation in cerebellar cultures, using T0901317 and 25hydroxycholesterol, enhanced expression of myelin-associated proteins, likely through transcriptional changes, while reverting the demyelinating phenotype in an LXR-dependent fashion (69). This study points to a potentially beneficial effect of LXR agonists on CNS remyelination and reduced neuronal damage. Notably, a loss of function mutation in the NR1H3 gene encoding LXR $\alpha$ in patients presenting with a rare genetic form of severe progressive MS, indicates that aberrant LXR signaling could be involved in MS progression (120). The synthetic LXR agonist T0901317 restored LXR-mediated ABCA1 expression in a cell-line transfected with the mutant LXR, suggesting that pharmacological activation of LXRs could be beneficial in progressive MS.

Strategies for tissue specific delivery are important in addressing the challenge of delivering therapeutic agents across the $\mathrm{BBB}$ during progressive MS, when inflammation is largely restricted within the CNS. Interestingly, a highly brain penetrant partial LXR $\alpha /$ full LXR $\beta$ agonist (LXR-623) had beneficial effects in a murine model of glioblastoma (112). However, in healthy volunteers LXR-623 showed adverse neurological effects at higher doses (111). Another study in healthy subjects using LXR $\beta$ selective agonist BMS-852927, showed enhanced cholesterol transport in human macrophages but also SREBP1c-induced lipogenesis which had not been predicted from primate models (113). Thus limitations exist using animal models to predict therapeutic responses in humans. Differences in TLR4 regulation between human and rodent cells $(121,122)$, treatment duration in culture (121) and differing eicosanoid regulation by $\operatorname{LXR}(58,123)$ have been reported and could underpin some limitations of the first generation LXR ligands.

Targeting LXRs in specific cell types or tissues could yield promising results for LXR-based therapeutics. For instance, atherosclerotic plaque-targeting nanoparticles encapsulating LXR ligands upregulate LXR target genes (including cholesterol

\section{REFERENCES}

1. Brownlee WJ, Hardy TA, Fazekas F, Miller DH. Diagnosis of multiple sclerosis: progress and challenges. Lancet (2017) 389(10076):1336-46. doi: 10.1016/S0140-6736(16)30959-X efflux genes) and downregulate proinflammatory mediators in macrophages in vitro and reduce macrophage frequency and promote regression in plaques without adverse effects on hepatic lipid metabolism in vivo (124-128). Similar strategies show promise at inhibiting inflammation (129), promoting resolution of inflammation (130) and improving apoptotic cell clearance through phagocytosis using gold nanocages loaded with LXR ligands (131). These recent advances could expedite the path to clinical translation for LXR agonists. There is a lack of MS-focused research exploring beneficial effects of LXR activation using these novel delivery approaches but they have paved the way towards further exploration of LXR ligands as effective therapeutics against MS.

\section{DISCUSSION}

In conclusion, further investigation into the role of LXRs in MS immunopathogenesis is warranted. Activation of these receptors can modify the expression of cytokines and other immune mediators and polarize immune cells towards pro or antiinflammatory phenotypes (Figure 1). In experimental models, LXR activation can ameliorate clinical symptoms. The role of LXRs has focused primarily on $\mathrm{CD} 4^{+} \mathrm{T}$-cells and myeloid cells. However, the impact of lipid metabolism on other immune cells, particularly B-cells, is unexplored and could provide further insight into MS immunopathogenesis. Alternative strategies may focus on the modulation of immune cell function through lipid rafts.

Thus, dysregulated LXR-mediated pathways are likely to contribute to MS pathogenesis and provide a cohesive model describing the disease manifestations. A better understanding of LXRs in the context of MS is needed before their promising therapeutic potential can be fully realized.

\section{AUTHOR CONTRIBUTIONS}

SS researched and wrote a first draft of the review. KW, RF, IP-T, and EJ revised the manuscript. All authors contributed to the article and approved the submitted version.

\section{FUNDING}

This work was supported by a project grant from the MS Society (Ref. 076) to IP-T, RF, and EJ.

2. Confavreux C, Vukusic S, Moreau T, Adeleine P. Relapses and progression of disability in multiple sclerosis. N Engl J Med (2000) 343(20):1430-8. doi: 10.1056/NEJM200011163432001

3. Mallucci G, Peruzzotti-Jametti L, Bernstock JD, Pluchino S. The role of immune cells, glia and neurons in white and gray matter pathology in 
multiple sclerosis. Prog Neurobiol (2015) 127-128:1-22. doi: 10.1016/ j.pneurobio.2015.02.003

4. Patani R, Balaratnam M, Vora A, Reynolds R. Remyelination can be extensive in multiple sclerosis despite a long disease course. Neuropathol Appl Neurobiol (2007) 33(3):277-87. doi: 10.1111/j.1365-2990.2007.00805.x

5. Filippi M, Bar-Or A, Piehl F, Preziosa P, Solari A, Vukusic S, et al. Multiple sclerosis. Nat Rev Dis Primers (2018) 4(1):43. doi: 10.1038/s41572-0180041-4

6. Dendrou CA, Fugger L, Friese MA. Immunopathology of multiple sclerosis. Nat Rev Immunol (2015) 15:545. doi: 10.1038/nri3871

7. Fiol MP, Ysrraelit MC, Gaitán MI, Correale J. Progressive multiple sclerosis: from pathogenic mechanisms to treatment. Brain. (2016) 140(3):527-46. doi: 10.1093/brain/aww258

8. van de Kraats C, Killestein J, Popescu V, Rijkers E, Vrenken H, Lutjohann D, et al. Oxysterols and cholesterol precursors correlate to magnetic resonance imaging measures of neurodegeneration in multiple sclerosis. Mult Scler (2014) 20(4):412-7. doi: 10.1177/1352458513499421

9. Ďurfinová $M$, Procházková Ľ, Petrleničová $D$, Bystrická $Z$, Orešanská $K$, Kuračka L̆, et al. Cholesterol level correlate with disability score in patients with relapsing-remitting form of multiple sclerosis. Neurosci Lett (2018) 687:304-7. doi: 10.1016/j.neulet.2018.10.030

10. Uher T, Fellows K, Horakova D, Zivadinov R, Vaneckova M, Sobisek L, et al. Serum lipid profile changes predict neurodegeneration in interferon- $\beta 1 \mathrm{a}-$ treated multiple sclerosis patients. J Lipid Res (2017) 58(2):403-11. doi: 10.1194/jlr.M072751

11. Weinstock-Guttman B, Zivadinov R, Horakova D, Havrdova E, Qu J, Shyh $\mathrm{G}$, et al. Lipid profiles are associated with lesion formation over 24 months in interferon- $\beta$ treated patients following the first demyelinating event. $J$ Neurology Neurosurg Psychiatry (2013) 84(11):1186-91. doi: 10.1136/jnnp2012-304740

12. Cantuti-Castelvetri L, Fitzner D, Bosch-Queralt M, Weil M-T, Su M, Sen P, et al. Defective cholesterol clearance limits remyelination in the aged central nervous system. Science (2018) 359(6376):684-8. doi: 10.1126/ science.aan 4183

13. Hubler Z, Allimuthu D, Bederman I, Elitt MS, Madhavan M, Allan KC, et al. Accumulation of 8,9-unsaturated sterols drives oligodendrocyte formation and remyelination. Nature (2018) 560(7718):372-6. doi: 10.1038/s41586018-0360-3

14. Waddington KE, Papadaki A, Coelewij L, Adriani M, Nytrova P, Kubala Havrdova E, et al. Using Serum Metabolomics to Predict Development of Anti-drug Antibodies in Multiple Sclerosis Patients Treated With IFN $\beta$. Front Immunol (2020) 11:1527. doi: 10.3389/fimmu.2020.01527

15. Grassi S, Giussani P, Mauri L, Prioni S, Sonnino S, Prinetti A. Lipid rafts and neurodegeneration: structural and functional roles in physiologic aging and neurodegenerative diseases. J Lipid Res (2020) 61(5):636-54. doi: 10.1194/ jlr.TR119000427

16. Howie D, Ten Bokum A, Necula AS, Cobbold SP, Waldmann H. The Role of Lipid Metabolism in T Lymphocyte Differentiation and Survival. Front Immunol (2018) 8:1949. doi: 10.3389/fimmu.2017.01949

17. Spann NJ, Glass CK. Sterols and oxysterols in immune cell function. Nat Immunol (2013) 14(9):893-900. doi: 10.1038/ni.2681

18. Lochner M, Berod L, Sparwasser T. Fatty acid metabolism in the regulation of $\mathrm{T}$ cell function. Trends Immunol (2015) 36(2):81-91. doi: 10.1016/ j.it.2014.12.005

19. Berod L, Friedrich C, Nandan A, Freitag J, Hagemann S, Harmrolfs K, et al. De novo fatty acid synthesis controls the fate between regulatory $\mathrm{T}$ and $\mathrm{T}$ helper 17 cells. Nat Med (2014) 20(11):1327-33. doi: 10.1038/nm.3704

20. Miguel L, Owen DM, Lim C, Liebig C, Evans J, Magee AI, et al. Primary human $\mathrm{CD} 4+\mathrm{T}$ cells have diverse levels of membrane lipid order that correlate with their function. J Immunol (2011) 186(6):3505-16. doi: 10.4049/jimmunol.1002980

21. Robinson GA, Waddington KE, Pineda-Torra I, Jury EC. Transcriptional regulation of t-cell lipid metabolism: implications for plasma membrane lipid rafts and t-cell function. Front Immunol (2017) 8:1636. doi: 10.3389/ fimmu.2017.01636

22. Varshney P, Yadav V, Saini N. Lipid rafts in immune signalling: current progress and future perspective. Immunology (2016) 149(1):13-24. doi: 10.1111/imm.12617
23. Waddington KE, Jury EC. Manipulating membrane lipid profiles to restore T-cell function in autoimmunity. Biochem Soc Trans (2015) 43(4):745-51. doi: 10.1042/BST20150111

24. McDonald G, Deepak S, Miguel L, Hall CJ, Isenberg DA, Magee AI, et al. Normalizing glycosphingolipids restores function in CD4+ T cells from lupus patients. J Clin Invest (2014) 124(2):712-24. doi: 10.1172/JCI69571

25. Yang W, Bai Y, Xiong Y, Zhang J, Chen S, Zheng X, et al. Potentiating the antitumour response of CD8+ T cells by modulating cholesterol metabolism. Nature (2016) 531(7596):651-5. doi: 10.1038/nature17412

26. Pihl-Jensen G, Tsakiri A, Frederiksen JL. Statin Treatment in Multiple Sclerosis: A Systematic Review and Meta-Analysis. CNS Drugs (2015) 29 (4):277-91. doi: 10.1007/s40263-015-0239-x

27. Chataway J, Schuerer N, Alsanousi A, Chan D, MacManus D, Hunter K, et al. Effect of high-dose simvastatin on brain atrophy and disability in secondary progressive multiple sclerosis (MS-STAT): a randomised, placebo-controlled, phase 2 trial. Lancet (2014) 383(9936):2213-21. doi: 10.1016/S0140-6736(13)62242-4

28. Youssef S, Stüve O, Patarroyo JC, Ruiz PJ, Radosevich JL, Hur EM, et al. The HMG-CoA reductase inhibitor, atorvastatin, promotes a Th2 bias and reverses paralysis in central nervous system autoimmune disease. Nature (2002) 420(6911):78-84. doi: 10.1038/nature01158

29. Zhang X, Tao Y, Wang J, Garcia-Mata R, Markovic-Plese S. Simvastatin inhibits secretion of Th17-polarizing cytokines and antigen presentation by DCs in patients with relapsing remitting multiple sclerosis. Eur J Immunol (2013) 43(1):281-9. doi: 10.1002/eji.201242566

30. Zhang X, Tao Y, Troiani L, Markovic-Plese S. Simvastatin Inhibits IFN Regulatory Factor 4 Expression and Th17 Cell Differentiation in CD4+ T Cells Derived from Patients with Multiple Sclerosis. J Immunol (2011) 187 (6):3431-7. doi: 10.4049/jimmunol.1100580

31. Eshaghi A, Kievit RA, Prados F, Sudre CH, Nicholas J, Cardoso MJ, et al. Applying causal models to explore the mechanism of action of simvastatin in progressive multiple sclerosis. Proc Natl Acad Sci (2019) 116(22):11020-7. doi: 10.1073/pnas.1818978116

32. Dunn SE, Youssef S, Goldstein MJ, Prod'homme T, Weber MS, Zamvil SS, et al. Isoprenoids determine Th1/Th2 fate in pathogenic T cells, providing a mechanism of modulation of autoimmunity by atorvastatin. J Exp Med (2006) 203(2):401-12. doi: 10.1084/jem.20051129

33. Bensinger SJ, Tontonoz P. Integration of metabolism and inflammation by lipid-activated nuclear receptors. Nature (2008) 454(7203):470-7. doi: 10.1038/nature07202

34. Ferret-Sena V, Capela C, Sena A. Metabolic Dysfunction and Peroxisome Proliferator-Activated Receptors (PPAR) in Multiple Sclerosis. Int J Mol Sci (2018) 19(6):1639. doi: 10.3390/ijms19061639

35. Waddington KE, Jury EC, Pineda-Torra I. Liver X receptors in immune cell function in humans. Biochem Soc Trans (2015) 43(4):752-7. doi: 10.1042/ BST20150112

36. Hong C, Tontonoz P. Liver X receptors in lipid metabolism: opportunities for drug discovery. Nat Rev Drug Discov (2014) 13(6):433-44. doi: 10.1038/ $\operatorname{nrd} 4280$

37. Pascual-García M, Valledor AF. Biological roles of liver X receptors in immune cells. Arch Immunol Ther Exp (Warsz) (2012) 60(4):235-49. doi: 10.1007/s00005-012-0179-9

38. Glaría E, Letelier NA, Valledor AF. Integrating the roles of liver X receptors in inflammation and infection: mechanisms and outcomes. Curr Opin Pharmacol (2020) 53:55-65. doi: 10.1016/j.coph.2020.05.001

39. Calkin AC, Tontonoz P. Transcriptional integration of metabolism by the nuclear sterol-activated receptors LXR and FXR. Nat Rev Mol Cell Biol (2012) 13(4):213-24. doi: $10.1038 / \mathrm{nrm} 3312$

40. Repa JJ, Mangelsdorf DJ. The role of orphan nuclear receptors in the regulation of cholesterol homeostasis. Annu Rev Cell Dev Biol (2000) 16:459-81. doi: 10.1146/annurev.cellbio.16.1.459

41. Janowski BA, Willy PJ, Devi TR, Falck JR, Mangelsdorf DJ. An oxysterol signalling pathway mediated by the nuclear receptor LXR $\alpha$. Nature (1996) 383(6602):728-31. doi: 10.1038/383728a0

42. Fu X, Menke JG, Chen Y, Zhou G, MacNaul KL, Wright SD, et al. 27hydroxycholesterol is an endogenous ligand for liver $\mathrm{X}$ receptor in cholesterol-loaded cells. J Biol Chem (2001) 276(42):38378-87. doi: 10.1074/jbc.M105805200 
43. Lehmann JM, Kliewer SA, Moore LB, Smith-Oliver TA, Oliver BB, Su JL, et al. Activation of the nuclear receptor LXR by oxysterols defines a new hormone response pathway. J Biol Chem (1997) 272(6):3137-40. doi: 10.1074/jbc.272.6.3137

44. Forman BM, Ruan B, Chen J, Schroepfer GJ, Evans RM. The orphan nuclear receptor LXR $\alpha$ is positively and negatively regulated by distinct products of mevalonate metabolism. Proc Natl Acad Sci (1997) 94(20):10588-93. doi: 10.1073/pnas.94.20.10588

45. Yang C, McDonald JG, Patel A, Zhang Y, Umetani M, Xu F, et al. Sterol intermediates from cholesterol biosynthetic pathway as liver $\mathrm{X}$ receptor ligands. J Biol Chem (2006) 281(38):27816-26. doi: 10.1074/jbc.M603781200

46. Collins JL, Fivush AM, Watson MA, Galardi CM, Lewis MC, Moore LB, et al. Identification of a Nonsteroidal Liver X Receptor Agonist through Parallel Array Synthesis of Tertiary Amines. J Med Chem (2002) 45(10):1963-6. doi: $10.1021 / j m 0255116$

47. Kumar N, Solt LA, Conkright JJ, Wang Y, Istrate MA, Busby SA, et al. The benzenesulfonamide T0901317 is a novel ROR $\alpha / \gamma$ Inverse Agonist. Mol Pharmacol (2010) 77(2):228-36. doi: 10.1124/mol.109.060905

48. Kanno Y, Tanuma N, Takahashi A, Inouye Y. TO901317, a potent LXR agonist, is an inverse agonist of CAR. J Toxicol Sci (2013) 38(3):309-15. doi: $10.2131 /$ jts. 38.309

49. Houck KA, Borchert KM, Hepler CD, Thomas JS, Bramlett KS, Michael LF, et al. T0901317 is a dual LXR/FXR agonist. Mol Genet Metab (2004) 83 (1):184-7. doi: 10.1016/j.ymgme.2004.07.007

50. Costet P, Lalanne F, Gerbod-Giannone MC, Molina JR, Fu X, Lund EG, et al. Retinoic Acid Receptor-Mediated Induction of ABCA1 in Macrophages. Mol Cell Biol (2003) 23(21):7756-66. doi: 10.1128/MCB.23.21.7756-7766.2003

51. Venkateswaran A, Laffitte BA, Joseph SB, Mak PA, Wilpitz DC, Edwards PA, et al. Control of cellular cholesterol efflux by the nuclear oxysterol receptor LXR $\alpha$. Proc Natl Acad Sci (2000) 97(22):12097-102. doi: 10.1073/ pnas. 200367697

52. Laffitte BA, Repa JJ, Joseph SB, Wilpitz DC, Kast HR, Mangelsdorf DJ, et al. LXRs control lipid-inducible expression of the apolipoprotein E gene in macrophages and adipocytes. Proc Natl Acad Sci (2001) 98(2):507-12. doi: 10.1073/pnas.98.2.507

53. Zanotti I, Potì F, Pedrelli M, Favari E, Moleri E, Franceschini G, et al. The LXR agonist T0901317 promotes the reverse cholesterol transport from macrophages by increasing plasma efflux potential. J Lipid Res (2008) 49 (5):954-60. doi: 10.1194/jlr.M700254-JLR200

54. Honzumi S, Shima A, Hiroshima A, Koieyama T, Ubukata N, Terasaka N. LXRalpha regulates human CETP expression in vitro and in transgenic mice. Atherosclerosis (2010) 212(1):139-45. doi: 10.1016/j.atherosclerosis.2010.04.025

55. Zelcer N, Hong C, Boyadjian R, Tontonoz P. LXR regulates cholesterol uptake through Idol-dependent ubiquitination of the LDL receptor. Science (2009) 325(5936):100-4. doi: 10.1126/science.1168974

56. Rigamonti E, Helin L, Lestavel S, Mutka AL, Lepore M, Fontaine C, et al. Liver X Receptor Activation Controls Intracellular Cholesterol Trafficking and Esterification in Human Macrophages. Circ Res (2005) 97(7):682-9. doi: 10.1161/01.RES.0000184678.43488.9f

57. Wang B, Tontonoz P. Liver X receptors in lipid signalling and membrane homeostasis. Nat Rev Endocrinol (2018) 14(8):452-63. doi: 10.1038/s41574018-0037-x

58. Rong X, Albert CJ, Hong C, Duerr MA, Chamberlain BT, Tarling EJ, et al. LXRs regulate ER stress and inflammation through dynamic modulation of membrane phospholipid composition. Cell Metab (2013) 18(5):685-97. doi: 10.1016/j.cmet.2013.10.002

59. Jalil A, Bourgeois T, Ménégaut L, Lagrost L, Thomas C, Masson D. Revisiting the Role of LXRs in PUFA Metabolism and Phospholipid Homeostasis. Int $J$ Mol Sci (2019) 20(15):3787. doi: 10.3390/ijms20153787

60. Laffitte BA, Joseph SB, Chen M, Castrillo A, Repa J, Wilpitz D, et al. The phospholipid transfer protein gene is a liver $\mathrm{X}$ receptor target expressed by macrophages in atherosclerotic lesions. Mol Cell Biol (2003) 23(6):2182-91. doi: 10.1128/MCB.23.6.2182-2191.2003

61. Zhang J, Liu Q. Cholesterol metabolism and homeostasis in the brain. Protein Cell (2015) 6(4):254-64. doi: 10.1007/s13238-014-0131-3

62. Björkhem I, Meaney S. Brain cholesterol: long secret life behind a barrier. Arterioscler Thromb Vasc Biol (2004) 24(5):806-15. doi: 10.1161/ 01.ATV.0000120374.59826.1b
63. Pfrieger FW, Ungerer N. Cholesterol metabolism in neurons and astrocytes. Prog Lipid Res (2011) 50(4):357-71. doi: 10.1016/j.plipres.2011.06.002

64. Ito A, Hong C, Rong X, Zhu X, Tarling EJ, Hedde PN, et al. LXRs link metabolism to inflammation through Abcal-dependent regulation of membrane composition and TLR signaling. Elife (2015) 4:e08009. doi: 10.7554/eLife.08009

65. Hindinger C, Hinton DR, Kirwin SJ, Atkinson RD, Burnett ME, Bergmann CC, et al. Liver $\mathrm{X}$ receptor activation decreases the severity of experimental autoimmune encephalomyelitis. J Neurosci Res (2006) 84(6):1225-34. doi: $10.1002 /$ jnr.21038

66. Cui G, Qin X, Wu L, Zhang Y, Sheng X, Yu Q, et al. Liver X receptor (LXR) mediates negative regulation of mouse and human Th17 differentiation. J Clin Invest (2011) 121(2):658-70. doi: 10.1172/JCI42974

67. Ma X, Bi E, Huang C, Lu Y, Xue G, Guo X, et al. Cholesterol negatively regulates IL-9-producing $\mathrm{CD} 8(+) \mathrm{T}$ cell differentiation and antitumor activity. J Exp Med (2018) 215(6):1555-69. doi: 10.1084/jem.20171576

68. Michaels AJ, Campbell C, Bou-Puerto R, Rudensky AY. Nuclear receptor LXR $\beta$ controls fitness and functionality of activated T cells. J Exp Med (2020) 218(4):e20201311. doi: 10.1084/jem.20201311

69. Meffre D, Shackleford GG, Hichor M, Gorgievski V, Tzavara ET, Trousson $A$, et al. Liver $\mathrm{X}$ receptors alpha and beta promote myelination and remyelination in the cerebellum. Proc Natl Acad Sci (2015) 112(24):758792. doi: $10.1073 /$ pnas. 1424951112

70. Boven LA, Van Meurs M, Van Zwam M, Wierenga-Wolf A, Hintzen RQ, Boot RG, et al. Myelin-laden macrophages are anti-inflammatory, consistent with foam cells in multiple sclerosis. Brain (2005) 129(2):517-26. doi: 10.1093/brain/awh707

71. Nelissen K, Mulder M, Smets I, Timmermans S, Smeets K, Ameloot M, et al. Liver X receptors regulate cholesterol homeostasis in oligodendrocytes. J Neurosci Res (2012) 90(1):60-71. doi: 10.1002/jnr.22743

72. Marangon D, Boccazzi M, Lecca D, Fumagalli M. Regulation of Oligodendrocyte Functions: Targeting Lipid Metabolism and Extracellular Matrix for Myelin Repair. J Clin Med (2020) 9(2):470. doi: 10.3390/ jcm9020470

73. Dimas P, Montani L, Pereira JA, Moreno D, Trötzmüller M, Gerber J, et al. CNS myelination and remyelination depend on fatty acid synthesis by oligodendrocytes. eLife (2019) 8:e44702. doi: 10.7554/eLife.44702

74. Zhornitsky S, McKay KA, Metz LM, Teunissen CE, Rangachari M. Cholesterol and markers of cholesterol turnover in multiple sclerosis: relationship with disease outcomes. Mult Scler Relat Disord (2016) 5:5365. doi: 10.1016/j.msard.2015.10.005

75. Browne RW, Weinstock-Guttman B, Horakova D, Zivadinov R, Bodziak ML, Tamaño-Blanco M, et al. Apolipoproteins are associated with new MRI lesions and deep grey matter atrophy in clinically isolated syndromes. J Neurology Neurosurg Psychiatry (2014) 85(8):859-64. doi: 10.1136/jnnp2013-307106

76. Tettey P, Simpson S, Taylor B, Blizzard L, Ponsonby A-L, Dwyer T, et al. An adverse lipid profile is associated with disability and progression in disability, in people with MS. Mult Scler J (2014) 20(13):1737-44. doi: 10.1177/ 1352458514533162

77. Gafson AR, Thorne T, McKechnie CIJ, Jimenez B, Nicholas R, Matthews PM. Lipoprotein markers associated with disability from multiple sclerosis. Sci Rep (2018) 8(1):17026. doi: 10.1038/s41598-018-35232-7

78. Fellows K, Uher T, Browne RW, Weinstock-Guttman B, Horakova D, Posova H, et al. Protective associations of HDL with blood-brain barrier injury in multiple sclerosis patients. J Lipid Res (2015) 56(10):2010-8. doi: 10.1194/jlr.M060970

79. Murali N, Browne RW, Fellows Maxwell K, Bodziak ML, Jakimovski D, Hagemeier J, et al. Cholesterol and neurodegeneration: longitudinal changes in serum cholesterol biomarkers are associated with new lesions and gray matter atrophy in multiple sclerosis over 5 years of follow-up. Eur J Neurol (2020) 27(1):188-e4. doi: 10.1111/ene.14055

80. Mukhopadhyay S, Fellows K, Browne RW, Khare P, Krishnan Radhakrishnan S, Hagemeier J, et al. Interdependence of oxysterols with cholesterol profiles in multiple sclerosis. Mult Scler (2017) 23(6):792-801. doi: $10.1177 / 1352458516666187$

81. Sodero AO. 24S-hydroxycholesterol: Cellular effects and variations in brain diseases. J Neurochem (2020) 1-20. doi: 10.1111/jnc.15228 
82. Leoni V, Masterman T, Diczfalusy U, De Luca G, Hillert J, Björkhem I. Changes in human plasma levels of the brain specific oxysterol 24Shydroxycholesterol during progression of multiple sclerosis. Neurosci Lett (2002) 331(3):163-6. doi: 10.1016/S0304-3940(02)00887-X

83. Fellows Maxwell K, Bhattacharya S, Bodziak ML, Jakimovski D, Hagemeier J, Browne RW, et al. Oxysterols and apolipoproteins in multiple sclerosis: a 5 year follow-up study. J Lipid Res (2019) 60(7):1190-8. doi: 10.1194/ jlr.M089664

84. van de Kraats C, Killestein J, Popescu V, Rijkers E, Vrenken H, Lütjohann D, et al. Oxysterols and cholesterol precursors correlate to magnetic resonance imaging measures of neurodegeneration in multiple sclerosis. Mult Scler J (2014) 20(4):412-7. doi: 10.1177/1352458513499421

85. Teunissen CE, Dijkstra CD, Polman CH, Hoogervorst ELJ, von Bergmann K, Lütjohann D. Decreased levels of the brain specific 24S-hydroxycholesterol and cholesterol precursors in serum of multiple sclerosis patients. Neurosci Lett (2003) 347(3):159-62. doi: 10.1016/S0304-3940(03)00667-0

86. Hu X, Wang Y, Hao LY, Liu X, Lesch CA, Sanchez BM, et al. Sterol metabolism controls $\mathrm{T}(\mathrm{H}) 17$ differentiation by generating endogenous ROR $\gamma$ agonists. Nat Chem Biol (2015) 11(2):141-7. doi: 10.1038/ nchembio. 1714

87. Vigne S, Chalmin F, Duc D, Clottu AS, Apetoh L, Lobaccaro J-MA, et al. IL27-Induced Type 1 Regulatory T-Cells Produce Oxysterols that Constrain IL-10 Production. Front Immunol (2017) 8:1184. doi: 10.3389/ fimmu.2017.01184

88. Giorelli M, Livrea P, Minervini MG, Trojano M. Immunomodulatory properties of increased levels of liver $\mathrm{X}$ receptor $\beta$ in peripheral blood mononuclear cells from multiple sclerosis patients. Exp Neurol (2007) 204 (2):759-66. doi: 10.1016/j.expneurol.2007.01.013

89. Hoppmann N, Graetz C, Paterka M, Poisa-Beiro L, Larochelle C, Hasan M, et al. New candidates for CD4 $\mathrm{T}$ cell pathogenicity in experimental neuroinflammation and multiple sclerosis. Brain (2015) 138(4):902-17. doi: 10.1093/brain/awu408

90. Wouters E, de Wit NM, Vanmol J, van der Pol SMA, van Het Hof B, Sommer D, et al. Liver X Receptor Alpha Is Important in Maintaining Blood-Brain Barrier Function. Front Immunol (2019) 10:1811. doi: 10.3389/ fimmu.2019.01811

91. Vergara D, D’Alessandro M, Rizzello A, De Riccardis L, Lunetti P, Del Boccio $\mathrm{P}$, et al. A lipidomic approach to the study of human CD4+ T lymphocytes in multiple sclerosis. BMC Neurosci (2015) 16(1):46. doi: 10.1186/s12868-015-0183-1

92. Halmer R, Walter S, Faßbender K. Sphingolipids: important players in multiple sclerosis. Cell Physiol Biochem (2014) 34(1):111-8. doi: 10.1159/ 000362988

93. Kurz J, Brunkhorst R, Foerch C, Blum L, Henke M, Gabriel L, et al. The relevance of ceramides and their synthesizing enzymes for multiple sclerosis. Clin Sci (2018) 132(17):1963-76. doi: 10.1042/CS20180506

94. Lötsch J, Schiffmann S, Schmitz K, Brunkhorst R, Lerch F, Ferreiros N, et al. Machine-learning based lipid mediator serum concentration patterns allow identification of multiple sclerosis patients with high accuracy. Sci Rep (2018) 8(1):14884. doi: 10.1038/s41598-018-33077-8

95. Chao CC, Gutiérrez-Vázquez C, Rothhammer V, Mayo L, Wheeler MA, Tjon EC, et al. Metabolic Control of Astrocyte Pathogenic Activity via cPLA2-MAVS. Cell (2019) 179(7):1483-98.e22. doi: 10.1016/ j.cell.2019.11.016

96. Waddington KE, Robinson GA, Rubio-Cuesta B, Chrifi-Alaoui E, Andreone S, Poon K-S, et al. LXR alters CD4+ T cell function through direct regulation of glycosphingolipid synthesis. bioRxiv (2020) 721050 . doi: $10.1101 / 721050$

97. Joseph SB, Castrillo A, Laffitte BA, Mangelsdorf DJ, Tontonoz P. Reciprocal regulation of inflammation and lipid metabolism by liver $\mathrm{X}$ receptors. Nat Med (2003) 9(2):213-9. doi: 10.1038/nm820

98. Landis MS, Patel HV, Capone JP. Oxysterol Activators of Liver X Receptor and 9-cis-Retinoic Acid Promote Sequential Steps in the Synthesis and Secretion of Tumor Necrosis Factor- $\alpha$ from Human Monocytes. J Biol Chem (2002) 277(7):4713-21. doi: 10.1074/jbc.M108807200

99. Zhang-Gandhi CX, Drew PD. iver X receptor and retinoid X receptor agonists inhibit inflammatory responses of microglia and astrocytes. J Neuroimmunol (2007) 183(1):50-9. doi: 10.1016/j.jneuroim.2006.11.007
100. Walcher D, Kümmel A, Kehrle B, Bach H, Grüb M, Durst R, et al. LXR Activation Reduces Proinflammatory Cytokine Expression in Human CD4Positive Lymphocytes. Arterioscler Thromb Vasc Biol (2006) 26(5):1022-8. doi: 10.1161/01.ATV.0000210278.67076.8f

101. Ghisletti S, Huang W, Ogawa S, Pascual G, Lin M-E, Willson TM, et al. Parallel SUMOylation-Dependent Pathways Mediate Gene- and SignalSpecific Transrepression by LXRs and PPAR\&x3b3. Mol Cell (2007) 25 (1):57-70. doi: 10.1016/j.molcel.2006.11.022

102. Guerrero BL, Sicotte NL. Microglia in Multiple Sclerosis: Friend or Foe? Front Immunol (2020) 11:374-. doi: 10.3389/fimmu.2020.00374

103. Mailleux J, Vanmierlo T, Bogie JF, Wouters E, Lütjohann D, Hendriks JJ, et al. Active liver $\mathrm{X}$ receptor signaling in phagocytes in multiple sclerosis lesions. Mult Scler J (2018) 24(3):279-89. doi: 10.1177/1352458517696595

104. Bogie JFJ, Timmermans S, Huynh-Thu VA, Irrthum A, Smeets HJM, Gustafsson J-Å, et al. Myelin-Derived Lipids Modulate Macrophage Activity by Liver X Receptor Activation. PloS One (2012) 7(9):e44998. doi: 10.1371/journal.pone.0044998

105. Bogie JFJ, Stinissen P, Hellings N, Hendriks JJA. Myelin-phagocytosing macrophages modulate autoreactive $\mathrm{T}$ cell proliferation. J Neuroinflammation (2011) 8:85-. doi: 10.1186/1742-2094-8-85

106. Xu J, Wagoner G, Douglas JC, Drew PD. Liver X receptor agonist regulation of Th17 lymphocyte function in autoimmunity. J Leukoc Biol (2009) 86 (2):401-9. doi: 10.1189/jlb.1008600

107. Wu L, Wen H, Zhou Y, Yu H, Liu Y, Bai L, et al. Activation of the liver X receptor inhibits Th17 and Th1 responses in Behcet's disease and VogtKoyanagi-Harada disease. Curr Mol Med (2014) 14(6):712-22. doi: 10.2174/ 1566524014666140724100135

108. Herold M, Breuer J, Hucke S, Knolle P, Schwab N, Wiendl H, et al. Liver X receptor activation promotes differentiation of regulatory T cells. PloS One (2017) 12(9):e0184985. doi: 10.1371/journal.pone.0184985

109. Fessler MB. The challenges and promise of targeting the Liver X Receptors for treatment of inflammatory disease. Pharmacol Ther (2018) 181:1-12. doi: 10.1016/j.pharmthera.2017.07.010

110. Xu P, Li D, Tang X, Bao X, Huang J, Tang Y, et al. LXR agonists: new potential therapeutic drug for neurodegenerative diseases. Mol Neurobiol (2013) 48(3):715-28. doi: 10.1007/s12035-013-8461-3

111. Katz A, Udata C, Ott E, Hickey L, Burczynski ME, Burghart P, et al. Safety, pharmacokinetics, and pharmacodynamics of single doses of LXR-623, a novel liver X-receptor agonist, in healthy participants. J Clin Pharmacol (2009) 49(6):643-9. doi: 10.1177/0091270009335768

112. Villa GR, Hulce J, Zanca C, Bi J, Ikegami S, Cahill GL, et al. An LXRCholesterol Axis Creates a Metabolic Co-Dependency for Brain Cancers. Cancer Cell (2016) 30(5):683-93. doi: 10.1016/j.ccell.2016.09.008

113. Kirchgessner TG, Sleph P, Ostrowski J, Lupisella J, Ryan CS, Liu X, et al. Beneficial and Adverse Effects of an LXR Agonist on Human Lipid and Lipoprotein Metabolism and Circulating Neutrophils. Cell Metab (2016) 24 (2):223-33. doi: 10.1016/j.cmet.2016.07.016

114. Muse ED, Yu S, Edillor CR, Tao J, Spann NJ, Troutman TD, et al. Cellspecific discrimination of desmosterol and desmosterol mimetics confers selective regulation of LXR and SREBP in macrophages. Proc Natl Acad Sci USA (2018) 115(20):E4680-e9. doi: 10.1073/pnas.1714518115

115. Yu S, Li S, Henke A, Muse ED, Cheng B, Welzel G, et al. Dissociated sterolbased liver $\mathrm{X}$ receptor agonists as therapeutics for chronic inflammatory diseases. FASEB J (2016) 30(7):2570-9. doi: 10.1096/fj.201600244R

116. Peng D, Hiipakka RA, Xie J-T, Dai Q, Kokontis JM, Reardon CA, et al. A novel potent synthetic steroidal liver $\mathrm{X}$ receptor agonist lowers plasma cholesterol and triglycerides and reduces atherosclerosis in LDLR(-/-) mice. Br J Pharmacol (2011) 162(8):1792-804. doi: 10.1111/j.14765381.2011.01202.x

117. Fessler MB. The Intracellular Cholesterol Landscape: Dynamic Integrator of the Immune Response. Trends Immunol (2016) 37(12):819-30. doi: 10.1016/ j.it.2016.09.001

118. Maczewsky J, Kaiser J, Krippeit-Drews P, Drews G. Approved LXR agonists exert unspecific effects on pancreatic $\beta$-cell function. Endocrine (2020) 68 (3):526-35. doi: 10.1007/s12020-020-02241-4

119. Zuercher WJ, Buckholz RG, Campobasso N, Collins JL, Galardi CM, Gampe RT, et al. Discovery of tertiary sulfonamides as potent liver $\mathrm{X}$ receptor antagonists. J Med Chem (2010) 53(8):3412-6. doi: 10.1021/jm901797p 
120. Wang Z, Sadovnick AD, Anthony L T, Ross JP, Bernales CQ, Encarnacion M, et al. Nuclear Receptor NR1H3 in Familial Multiple Sclerosis. Neuron (2016) 90(5):948-54. doi: 10.1016/j.neuron.2016.04.039

121. Fontaine C, Rigamonti E, Nohara A, Gervois P, Teissier E, Fruchart JC, et al. Liver $\mathrm{X}$ receptor activation potentiates the lipopolysaccharide response in human macrophages. Circ Res (2007) 101(1):40-9. doi: 10.1161/ CIRCRESAHA.106.135814

122. Töröcsik D, Baráth M, Benkő S, Széles L, Dezső B, Póliska S, et al. Activation of Liver X Receptor Sensitizes Human Dendritic Cells to Inflammatory Stimuli. J Immunol (2010) 184(10):5456-65. doi: 10.4049/jimmunol.0902399

123. Ishibashi M, Varin A, Filomenko R, Lopez T, Athias A, Gambert P, et al. Liver $\mathrm{x}$ receptor regulates arachidonic acid distribution and eicosanoid release in human macrophages: a key role for lysophosphatidylcholine acyltransferase 3. Arterioscler Thromb Vasc Biol (2013) 33(6):1171-9. doi: 10.1161/ATVBAHA.112.300812

124. Yu M, Amengual J, Menon A, Kamaly N, Zhou F, Xu X, et al. Targeted Nanotherapeutics Encapsulating Liver X Receptor Agonist GW3965 Enhance Antiatherogenic Effects without Adverse Effects on Hepatic Lipid Metabolism in Ldlr-/- Mice. Adv Healthc Mat (2017) 6(20):1700313. doi: 10.1002/adhm.201700313

125. He H, Yuan Q, Bie J, Wallace RL, Yannie PJ, Wang J, et al. Development of mannose functionalized dendrimeric nanoparticles for targeted delivery to macrophages: use of this platform to modulate atherosclerosis. Transl Res (2018) 193:13-30. doi: 10.1016/j.trsl.2017.10.008

126. Guo Y, Yuan W, Yu B, Kuai R, Hu W, Morin EE, et al. Synthetic HighDensity Lipoprotein-Mediated Targeted Delivery of Liver X Receptors Agonist Promotes Atherosclerosis Regression. EBioMedicine (2018) 28:225-33. doi: 10.1016/j.ebiom.2017.12.021

127. Yuan W, Yu B, Yu M, Kuai R, Morin EE, Wang H, et al. Synthetic highdensity lipoproteins delivering liver $\mathrm{X}$ receptor agonist prevent atherogenesis by enhancing reverse cholesterol transport. J Control Release (2021) 329:36171. doi: 10.1016/j.jconrel.2020.11.016

128. Smith TKT, Kahiel Z, LeBlond ND, Ghorbani P, Farah E, Al-Awosi R, et al. Characterization of Redox-Responsive LXR-Activating Nanoparticle Formulations in Primary Mouse Macrophages. Molecules (2019) 24 (20):3751. doi: 10.3390/molecules24203751

129. Zhang X-Q, Even-Or O, Xu X, van Rosmalen M, Lim L, Gadde S, et al. Nanoparticles Containing a Liver X Receptor Agonist Inhibit Inflammation and Atherosclerosis. Adv Healthc Mat (2015) 4(2):228-36. doi: 10.1002/ adhm. 201400337

130. Gadde S, Even-Or O, Kamaly N, Hasija A, Gagnon PG, Adusumilli KH, et al. Development of therapeutic polymeric nanoparticles for the resolution of inflammation. Adv Healthc Mater (2014) 3(9):1448-56. doi: 10.1002/ adhm.201300688

131. Xu N, Li J, Gao Y, Zhou N, Ma Q, Wu M, et al. Apoptotic cell-mimicking gold nanocages loaded with LXR agonist for attenuating the progression of murine systemic lupus erythematosus. Biomaterials (2019) 197:380-92. doi: 10.1016/j.biomaterials.2019.01.034

Conflict of Interest: The authors declare that the research was conducted in the absence of any commercial or financial relationships that could be construed as a potential conflict of interest.

Copyright (C) 2021 Pineda-Torra, Siddique, Waddington, Farrell and Jury. This is an open-access article distributed under the terms of the Creative Commons Attribution License (CC BY). The use, distribution or reproduction in other forums is permitted, provided the original author(s) and the copyright owner(s) are credited and that the original publication in this journal is cited, in accordance with accepted academic practice. No use, distribution or reproduction is permitted which does not comply with these terms. 